\title{
Melatonin Modulates the Immune System Response and Inflammation in Diabetic Rats Experimentally- Induced by Alloxan
}

Authors

Affiliations

\author{
S. Ozkanlar ${ }^{1}$, A. Kara ${ }^{2}$, E. Sengul ${ }^{3}$, N. Simsek ${ }^{4}$, A. Karadeniz ${ }^{5}$, N. Kurt ${ }^{6}$
}

Affiliation addresses are listed at the end of the article

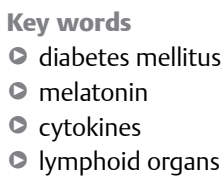

received $\quad 07.12 .2014$ accepted 30.03 .2015

\section{Bibliography}

DOI http://dx.doi.org/ 10.1055/s-0035-1548937

Published online:

May 4, 2015

Horm Metab Res 2016;

48: 137-144

(c) Georg Thieme Verlag KG

Stuttgart · New York

ISSN 0018-5043

\section{Correspondence}

\section{Dr. S. Ozkanlar}

Department of Biochemistry

Faculty of Veterinary Medicine University of Ataturk 25240 Erzurum

Turkey

Tel.: + 90/442/2315542

Fax: + 90/442/236 0881

seckinozkanlar@yahoo.com

\section{Abstract \\ $\nabla$}

Diabetes mellitus (DM) is a metabolic disease, which causes an increase in the proinflammatory cytokines tumor necrosis factor- $\alpha$ (TNF- $\alpha)$ and interleukin $1 \beta$ (IL-1 $\beta$ ), and also proliferation of monocyte chemotactic protein. In the present study, the potential effects of melatonin on proinflammatory cytokines, hematological values, and lymphoid tissues were investigated in diabetic rats. In the study, 36 male rats were randomly divided into 4 groups as follows: Control, Mel (melatonin), DM, and DM-Mel. For 15 days, an isotonic saline solution was given to the Control and DM groups; melatonin was administered to the Mel and DM-Mel groups intraperitoneally. At the end of the study, all animals were sacrificed by drawing the blood from their hearts

\section{Introduction}

$\nabla$

Diabetes mellitus (DM) is characterized by high blood glucose, polyuria, polydipsia, and polyphagia accompanied by insulin secretion from pancreatic $\beta$ cells that are insufficient to maintain blood glucose homeostasis [1]. DM is divided into 2 etiopathogenic groups. Type 1 diabetes mellitus (T1DM) is defined in the first category and is caused by the autoimmune destruction of $\beta$ cells. Type 2 diabetes mellitus (T2DM) is produced by conditions that reduce insulin sensitivity and negatively affect $\beta$-cell activities $[1,2]$. DM results in hyperglycemia, neuropathy, nephropathy, and retinopathy due to insulin deficiency or resistance and high blood glucose [2]. There is also some evidence suggesting that diabetics have a deficiency in inflammatory control [3]. Cytokines are chemical substances that have an important role in the immune response of many diseases, including type 1 diabetes [4]. Proinflammatory cytokines, such as interleukin- $1 \beta$ under deep anesthesia. Samples of the spleen, thymus, and lymph nodes were fixed in $10 \%$ formaldehyde for histologic analysis. Increases in proinflammatory serum cytokine concentrations, mast cells, and total white blood cell counts as well as tissue destruction in the lymphoid organs were determined in the DM group via biochemical, hematological, and histologic analyses. However, the findings for the DM-Mel group revealed decreases in serum IL- $1 \beta$ concentration and mast cell densities, and destructions in lymphoid tissues by the melatonin administration. The present study suggests that melatonin treatment may control immune system regulation and inhibit the production of proinflammatory cytokines and tissue mast cell accumulation by preventing the destruction of lymphoid organs in the diabetic process.

(IL-1 $\beta$ ) and tumor necrosis factor- $\alpha$ (TNF- $\alpha$ ), promote the destruction of pancreatic endocrine islets via islet-infiltrating immune cells [5]. It has been demonstrated that many functional abnormalities associated with diabetes can partially contribute to failure in appropriate inflammatory responses. Some researchers have suggested the concurrent occurrence of allergic disorders in T1DM [6]. In addition, it has been proposed that mast cells and eosinophil accumulation are decreased in the pleural cavity due to allergic reactions in diabetes mellitus patients [7]. Mast cells (MCs) have central effector and regulatory roles in inflammatory diseases (autoimmunity, allergic diseases, and parasitic infections) [8]. They are located in many tissues in the body, such as the airways, skin, gastrointestinal tract, and lymphoid tissues, and have the ability to release proinflammatory and immunoregulatory mediators [6]. The autoimmune response against islet $\beta$ cells is believed to result from a disorder of immunoregulation. Macrophages 
produce proinflammatory cytokines (IL- $1 \beta$ and TNF- $\alpha$ ). IFN $\gamma$ exert their cytotoxicity on $\beta$ cells in large part by inducing the formation of oxygen free radicals, nitric oxide, and peroxynitrite in the $\beta$ cells themselves [9]. TNF- $\alpha$ has an important key role in the pathogenesis of T2DM [10]. It has been shown that TNF- $\alpha$ induces insulin resistance to attenuate insulin receptor signaling and inhibit the activity of this hormone in animal experiments and cell cultures $[11,12]$. Eosinophils play an important role in allergic diseases due to MC activation, and they release other inflammatory mediators. Moreover, functional abnormalities of neutrophils, such as phagocytic activity and chemotaxis, have been reported in diabetic patients [7].

Researchers have reported an immune deficiency probably associated with a reduction in insulin secretion that occurs during the diabetic process [13]. In contrast, other researchers have found a direct correlation between hyperglycemia and infection incidence in diabetic patients. Later, still other researchers have reported the effects of platelet activating factor (PAF), leukotriene B (LTB), and some cytokines related with this concept $[14,15]$. However, the underlying mechanisms between diabetes mellitus and defects in the immune response have not yet been determined.

Melatonin (Mel) is a powerful antioxidant agent, and its actions are mediated through receptor-mediated and independent mechanisms [16,17]. Melatonin has been used for the treatment of some diseases related with oxidative stress [18-20]. In particular, the immune-modulatory effects of melatonin have been investigated in many studies and have shown its ability to control the immune response $[17,20,21]$. Additionally, bioregulatory effects of melatonin on peripheral organs such as skin were suggested by contributing to the melatoninergic antioxidative system of the skin [22-24].

The hypothesis of the present study on immune regulatory effects control is to find out whether melatonin coordinates inflammation and prevents the destruction of lymphoid tissues in diabetic rats. The aims of the study are to investigate the diabetic effects and the potential protective effects of melatonin on the immune system by means of hematologic values, inflammatory cytokines, and MC activation as well as histopathologic alterations in the spleen, thymus, and lymph nodes of rats with experimentally induced diabetes.

\section{Material and Methods}

$\nabla$

\section{Animal housing and experimental design}

Thirty-six male Sprague-Dawley rats weighing $180-200$ g were used in the study. The experiments were conducted according to the ethical norms approved by the Local Ethics Committee of Ataturk University for Animal Experiments (Decision No. HADYEK 2013-58). All animals were housed under standard laboratory conditions (light period from 06:00 AM to 7:00 PM, $21 \pm 2^{\circ} \mathrm{C}$, and relative humidity: $58 \%$ ). The rats were given water and fed a regular rat diet. All rats were divided into 4 groups as described below:

- The Control (C) group consisted of 9 animals who were not given any treatment throughout the study.

- The Melatonin (Mel) group included 9 animals who were given the melatonin treatment intraperitoneally (IP) at a dose of $10 \mathrm{mg} / \mathrm{kg}^{-1}$ per day for 15 days.

- The Diabetic (DM) group encompassed 9 animals who had been subjected to diabetes with an alloxan injection. After diabetes mellitus had developed, placebo treatment with intraperitoneal $0.5 \mathrm{ml}$ isotonic saline solution $(0.09 \% \mathrm{NaCl})$ per day was started and given for 15 days.

- The Diabetic-Melatonin (DM-Mel) group consisted of 9 animals who developed diabetes following an alloxan injection. After the diabetes mellitus became evident, melatonin treatment was started and given intraperitoneally at a dose of $10 \mathrm{mg} \mathrm{kg}^{-1}$ per day for 15 days.

\section{Melatonin preparation and administration}

Melatonin (Sigma Chemical Co. St. Louis, MO, USA) was freshly dissolved in a saline-ethanol $(0.01 \%)$ mixture and was administered IP at a daily dose of $10 \mathrm{mg} / \mathrm{kg}$ body weight according to previous animal studies $[20,25,26]$. Melatonin or the vehicle alone was administered at night for 15 consecutive days.

\section{Diabetic procedure}

For the DM and DM-Mel groups, experimental diabetes was induced by a single intraperitoneal injection of alloxan monohydrate (Sigma Co., USA) at a dose of $120 \mathrm{mg} / \mathrm{kg}^{-1}$ body weight dissolved in normal saline. To verify diabetes, blood glucose concentrations were measured using blood samples collected from the tail vein with a glucometer and test strips (Accu-Check Active $^{\circledR}$ ) at the first hour (before the initiation of trials) and 2 weeks later. The animals were then left alone for 2 weeks to allow for the stabilization of their blood glucose concentrations. On day 14 , the animals with a fasting blood glucose level higher than $220 \mathrm{mg} / \mathrm{dl}$ were considered diabetic and were therefore included in the study.

\section{Blood collection and tissue removing procedure}

After 15 days of melatonin treatment (at the end of the study), rats in all the groups were anesthetized with xylazine hydrochloride $\left(10 \mathrm{mg} / \mathrm{kg}^{-1}\right)$ (Rompun, Bayer, Turkey) and ketamine hydrochloride $\left(40 \mathrm{mg} / \mathrm{kg}^{-1}\right)$ (Ketalar, Pfizer, Turkey). Blood samples were individually collected from the heart of each rat, and then the animals were euthanized with an intracardiac thiopental sodium (Pentothal Sodium, Abbott) injection. The lymphoid tissues (spleen, thymus, and lymph nodes) of the euthanized rats were removed for histologic analysis and placed in $10 \%$ neutral formaldehyde solution.

\section{Hematologic and biochemical analysis}

The collected blood samples were centrifuged at $1500 \mathrm{~g}$ for 10 min within $1 \mathrm{~h}$ after collection to obtain sera samples. The sera were stored in the freezer at $-80^{\circ} \mathrm{C}$ before they were analyzed. For the hematologic analysis, complete blood counts, white blood cells (WBC), neutrophils (Neut), lymphocytes (Lym), and monocytes (Mon) in the blood samples with ethylenediaminetetraacetic acid (EDTA) were performed with a blood counter (Abacus Junior Vet5, Diatron, Austria).

\section{Interleukin 1 beta (IL-1 $\beta$ ) and tumor necrosis factor} alpha (TNF- $\alpha$ ) analysis

Serum IL-1 $\beta$ and TNF- $\alpha$ concentrations were measured using rat-specific sandwich enzyme-linked immunosorbent assay (ELISA) IL- $1 \beta$ and TNF- $\alpha$ immunoassay kits (Invitrogen, CA, USA). Analyses were performed according to the manufacturers' instructions. Briefly, monoclonal antibody specific for rat IL- $1 \beta$ and TNF- $\alpha$ were coated onto the wells of the micro plates. The samples, including standards of known rat IL- $1 \beta$ and TNF- $\alpha$ contents, control specimens, and sera samples were pipetted into 
these wells and then incubated for the first incubation to allow the antibodies to bind to the antigens for rat IL- $1 \beta$ and TNF- $\alpha$. After washing, a biotinylated monoclonal antibody specific for rat IL- $1 \beta$ and TNF- $\alpha$ was added. During the second incubation, the antibodies that were bound to the immobilized rat IL-1 $\beta$ and TNF- $\alpha$ were captured. After removal of excess second antibody, streptavidin-peroxidase (enzyme) was added. This enzyme bound to the biotinylated antibody was added to complete the 4-member sandwich. After a third incubation and washing to remove any remaining unbound enzyme, a substrate solution was added, which is acted upon by the bound enzyme to produce a color. The intensity of this colored product is directly proportional to the concentration of rat IL- $1 \beta$ and TNF- $\alpha$ present in the original specimen. At the end of the course, the well plates were read at $450 \mathrm{~nm}$ via an ELISA plate reader (Bio-Tek, $\mu$ Quant, USA). The absorbance of the samples was estimated with formulas that used standard graphics. All results are presented as $\mathrm{pg} / \mathrm{ml}$.

\section{Light microscopic analysis}

After the rats were sacrificed, their spleen, thymus, and lymph nodes were fixed in $10 \%$ neutral buffered formaldehyde for $72 \mathrm{~h}$. The fixed tissues were then dehydrated and embedded in paraffin, and serial sections were cut using a Leica RM2125RT microtome (Leica Microsystems, Wetzlar, Germany). Subsequently, we obtained a total of 20 serial and 4 randomly selected slides for each animal. Four sections were used for the determination of mast cells with enzyme histochemical esterase staining, and 4 sections were stained with Crossman-modified Mallory's triple staining for histopathological analysis. The histological inflammation activity and tissue alterations for all groups were evaluated by high-power light microscope (Nikon Eclipse 50i).

\section{Histopathologic evaluation procedure}

The histopathologist microscopically examined the samples stained with Crossman-modified Mallory's triple sections in a blinded fashion. Recording results were evaluated by examining 10 different areas with $20 \times$ objective for following lymphoid organs of each rat. The spleen, thymus, and lymph node-injury criteria were as follows: condensed cell density, parenchymal and capsular fibrosis, and apoptotic cell density for the spleen; cortex/medulla ratio, apoptotic cell density, and enlargement in cords for thymus; and condensed cell density, enlargement in cords, and polymorphonuclear cell (PMNL) densities for the lymph nodes. Each criterion was scored as follows: -, normal; + , minimal change; ++ , mild change; and +++ , severe change. The lymphoid tissues of all rats in the groups were calculated by examining 4 histologic sections for each rat.

\section{Stereologic calculation procedure for MC densities}

For the stereologic estimation, serial sections of the spleen, thymus, and lymph nodes were examined by the stereologic fractionator method, which utilizes random, systematic sampling to provide unbiased and quantitative data. This technique provides quantitative information about 3-dimensional material from measurements conducted with 2-dimensional planar sections of the material. In all tissues of each group, the numerical densities of MCs were estimated via the stereologic fractionator method. Stereological analyses were performed at a stereology workstation consisting of a modified light microscope, a motorized specimen stage for automatic sampling, a CCD color video camera, and stereology software. The unbiased counting frame fractionator combination is a stereological method for counting cells in the tissue sections $[27,28]$. In this study, unbiased counting frame and fractionator methods were used to estimate the numerical density of enzyme-histochemically stained MCs in the spleen, thymus, and lymph nodes. Each microscope slide was sampled using the fractionator principle of the stereology software. Cells were counted using a $40 \times$ Leica Plan Apo objective (NA=1.40), which allowed accurate recognition. Each MC was counted via the stereology software according to the unbiased counting frame. The numerical densities of the MCs were estimated according to the formula given below:

$\mathrm{Nd}=\mathrm{TM} / \mathrm{CFA} \times \mathrm{NSS}$,

where $\mathrm{Nd}$ is the MC numerical density, TM is total markers, CFA is the counting frame area $(\mathrm{XY})\left(\mu^{2}\right)$, and NSS is the number of sampling sites.

\section{Statistical analysis}

The statistical evaluation of present study was performed using the Statistical Package for the Social Sciences (SPSS) Version 17.0 (IBM Inc. NY, USA). The comparisons of the groups according to hematologic values, cytokine concentrations, and stereological data were analyzed by one-way ANOVA followed by Duncan post hoc test $(\mathrm{p}<0.05)$. All values are expressed as mean \pm standard deviation.

\section{Results}

$\nabla$

\section{Hematologic values}

In the hematologic analysis of white blood cell parameters, there was a significant increase in the WBC counts of the DM group compared with the Control group $(\mathrm{p}<0.05)$. Additionally, the Neut counts of the DM group tended to be increased compared with the Control group ( $\mathrm{p}$ 0.05). At the same time, WBC, Mon, and Neut counts were significantly decreased in the DM-Mel group when compared with the DM group $(\mathrm{p}<0.05)$, and there were no significant difference in Lym counts compared with the Control group ( $p>0.05$ ). Additionally, the parameters for WBCs, Mons, and Neuts significantly decreased in the Mel group $(\mathrm{p}<0.05)$, and the Lym count decreased insignificantly compared with the Control group ( $p>0.05)$. The comparisons of WBC, Lym, Mon, and Neut parameters are summarized in $\bullet$ Fig. 1.

\section{Serum cytokine concentration}

Serum IL- $1 \beta$ and TNF- $\alpha$ analyses revealed an increase in the concentrations of the DM group compared with the Control group. However, the IL-1 $\beta$ concentration slightly decreased in the DMMel group compared with the DM group $(p>0.05)$, but TNF- $\alpha$ concentration did not change in the DM-Mel group $(p>0.05)$. In addition, there was little increase in the levels of IL-1 $\beta$ and TNF- $\alpha$ concentrations in the Mel group ( $p>0.05)$. The IL- $1 \beta$ and TNF- $\alpha$ concentrations and the statistical comparisons among the groups are presented in $\bullet$ Fig. 2 .

\section{Histopathologic findings}

In the histopathologic analysis of the spleen and thymus for all groups, the animals in the Control and Mel groups had normal parenchyma and stroma. Additionally, sections from the DM group had severely condensed cells and fibrotic parenchyma and capsules. Conversely, the DM-Mel group showed less fibrosis and fewer condensed cells compared with the DM group (๑ Table 1 and $\odot$ Fig. 3 ). 


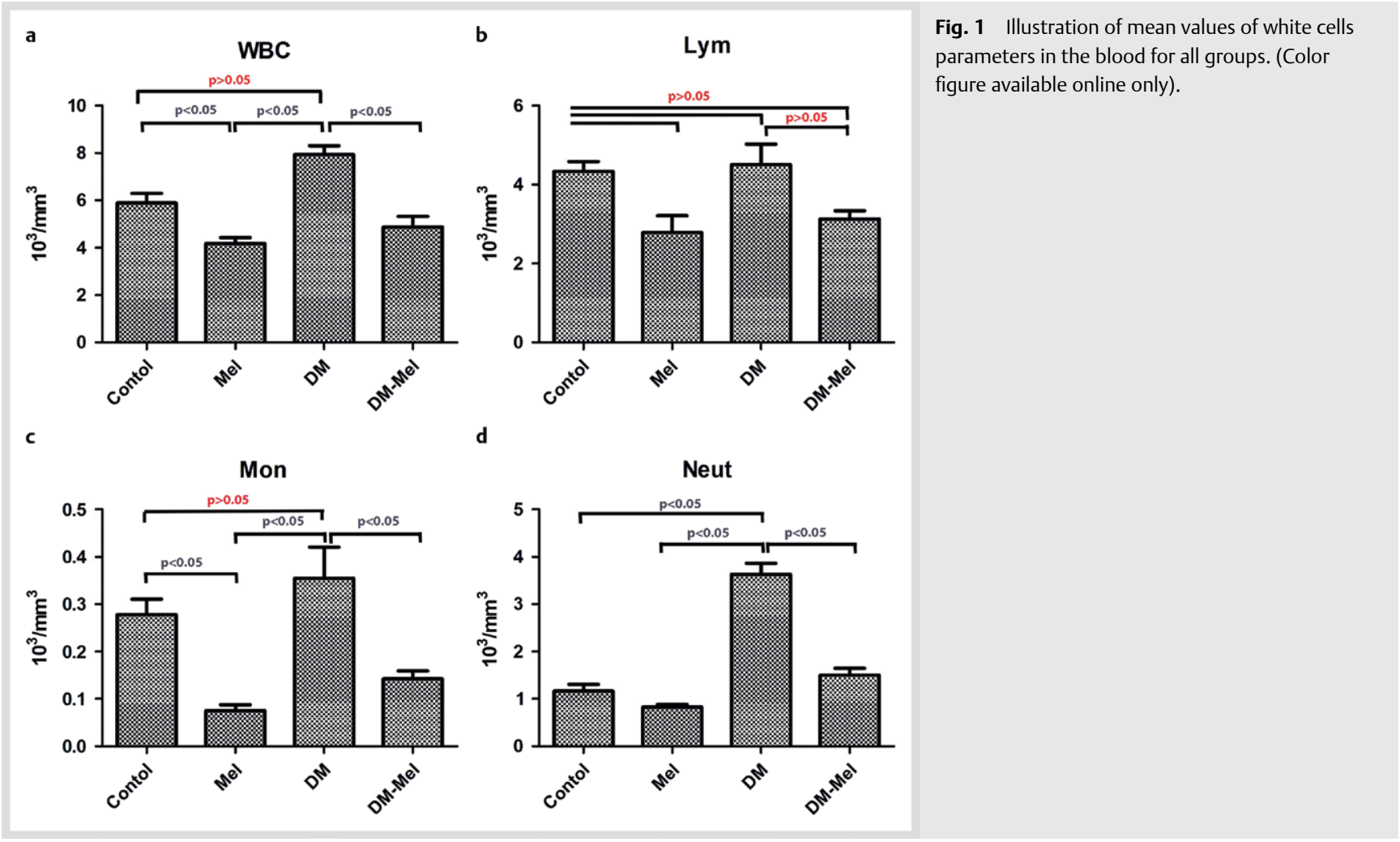

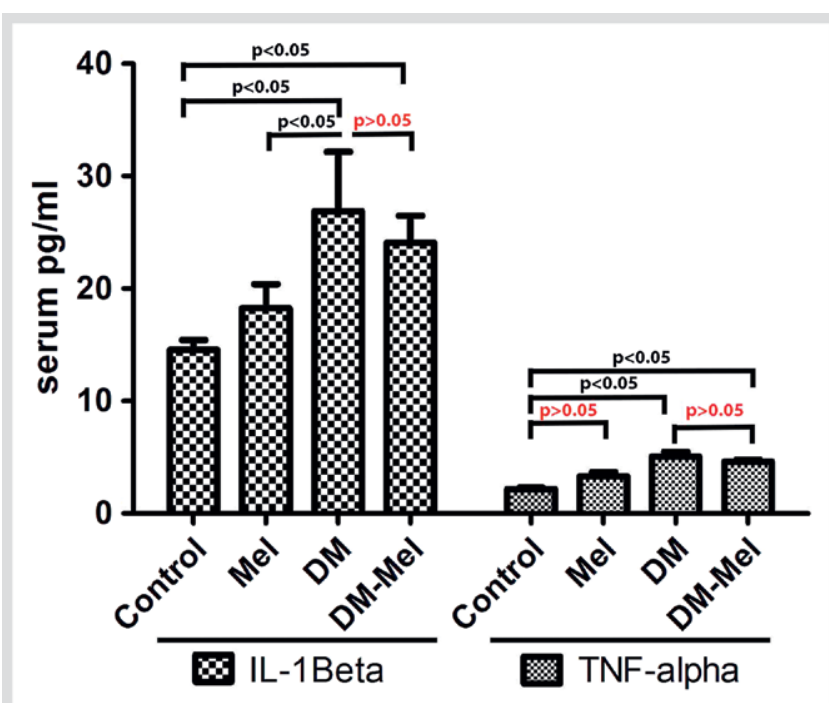

Fig. 2 Illustration of serum cytokine levels for all groups. (Color figure available online only).

Histopathologic analysis of the lymph nodes revealed normal histologic features in the control group section, and similarly normal histologic structures were observed in lymph node tissues of the animals in the Mel group except for the negligible dilatation of the medullary sinuses. Histopathologic analysis of DM group specimens also showed severely condensed cells, enlargement of the tertiary cortical nodules and medullary cords, and large numbers of free macrophages in the medullary sinuses; however, these pathologies were lessened by the melatonin treatment ( $\bullet$ Fig. 3). Histopathologic grades of all groups are presented in $\odot$ Table $\mathbf{1 .}$

\section{Stereologic estimation of MC density}

Enzyme histochemical esterase staining for MCs revealed that the highest MC density of the spleen was found in rats of the DM group, but rats in the DM-Mel group had a lower MC density $(\mathrm{p}<0.05)$. The rats in the control and Mel groups had lower MCs numbers in their spleen tissue ( $p>0.05$ ).

Stereologic estimation of thymus MC densities indicated a significant decrease in MC densities of the Mel group compared with other groups $(\mathrm{p}<0.05)$. MC densities of the DM and DMMel groups increased compared with the control group, and there was no statistically significant difference $(p>0.05)$.

Estimation of MC densities of lymph node tissue revealed an inhibitory effect of melatonin on MC distribution. A larger number of MC was observed in the Control and DM groups compared with the other groups $(\mathrm{p}<0.05)$. Dramatically, the lowest number of MCs was observed in the DM-Mel groups. Stereologic estimation of MC numbers per $10000 \mu \mathrm{m}^{2}$ area and comparisons among groups are presented in $\bullet$ Fig. 4,5.

\section{Discussion}

$\nabla$

Evidence of immune response alterations in diabetes has been reported in several studies $[3,9]$ regarding pathologic immune activity and inflammatory cell accumulations. According to some researchers $[20,29,30]$, diabetes mellitus is similar to some organ-specific autoimmune diseases in that it results from a dysregulation of immune responses. The present study was designed to investigate the potential regulatory effects of melatonin on the immune system, including cytokine activation, hematologic parameters, mast cell activation, and destruction of lymphoid organs in rats with experimentally induced diabetes. 
Table 1 Semi-quantitative analysis of the histopathological grades of the spleen, thymus, and lymph node tissues for all groups.

\begin{tabular}{llllllll} 
Groups & $\begin{array}{l}\text { Spleen } \\
\text { Condensed } \\
\text { cell density }\end{array}$ & $\begin{array}{l}\text { Parenchymal and } \\
\text { capsular fibrosis }\end{array}$ & $\begin{array}{l}\text { Thymus } \\
\text { Cortex/medulla } \\
\text { ratio }\end{array}$ & $\begin{array}{l}\text { Enlargement in } \\
\text { cords }\end{array}$ & $\begin{array}{l}\text { Lymph } \\
\text { Condensed cell } \\
\text { density }\end{array}$ & $\begin{array}{l}\text { Enlargement in } \\
\text { cords }\end{array}$ & $\begin{array}{l}\text { PMNL } \\
\text { density }\end{array}$ \\
Control & - & - & 0.399 & - & - & - & - \\
Mel & - & + & 0.475 & - & - & + & + \\
DM & +++ & ++ & 0.491 & +++ & ++ & ++ \\
DM-Mel & + & + & 0.396 & ++ & + & + \\
\hline Each criterion was scored as: -; normal, +; minimal change, ++; mild change, and +++, severe change & &
\end{tabular}

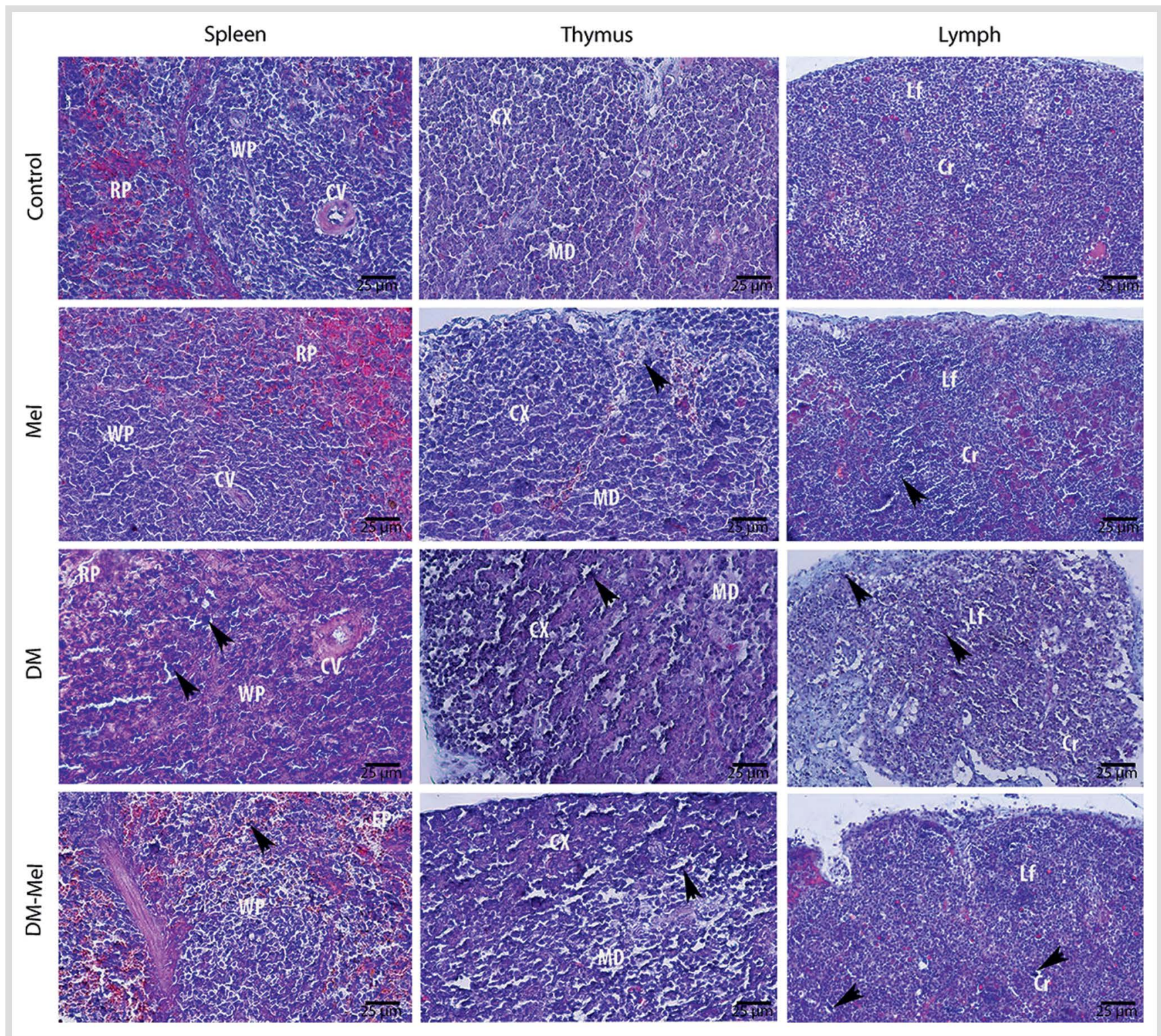

Fig. 3 Illustration of spleen, thymus, and lymph node tissues for all groups. CV: Central vein; WP: White pulp; RP: Red pulp; Cx: Cortex; MD: Medulla; Lf: Lymph follicle; Cr: Lymphatic cords. Arrows: condensed cells, Crossman-modified Mallory's triple staining. (Color figure available online only).

Hematologic parameters such as the neutrophil count are an indicator of injurious stimuli and are mostly part of an inflammatory response. In the present study, leukocytosis and elevated neutrophil counts were detected in the hematologic profile of the Diabetic group, while melatonin treatment induced a significant decrease in WBC counts. The increase in WBC counts of diabetes was associated with the pathophysiology of the diabetic process [31], whereas melatonin treatment can attenuate the hematologic parameters against the diabetic injury [17,32,33]. These results are in agreement with previous studies, which have suggested a decrease in the total leukocyte count following melatonin treatment $[34,35]$. The underlying mechanism of this melatonin-induced decrease in WBC count has not been clarified. However, some mechanisms are responsible for this action. The first possible mechanism is that melatonin may have inhibited hematopoiesis in either the bone marrow [35] or lymphatic 


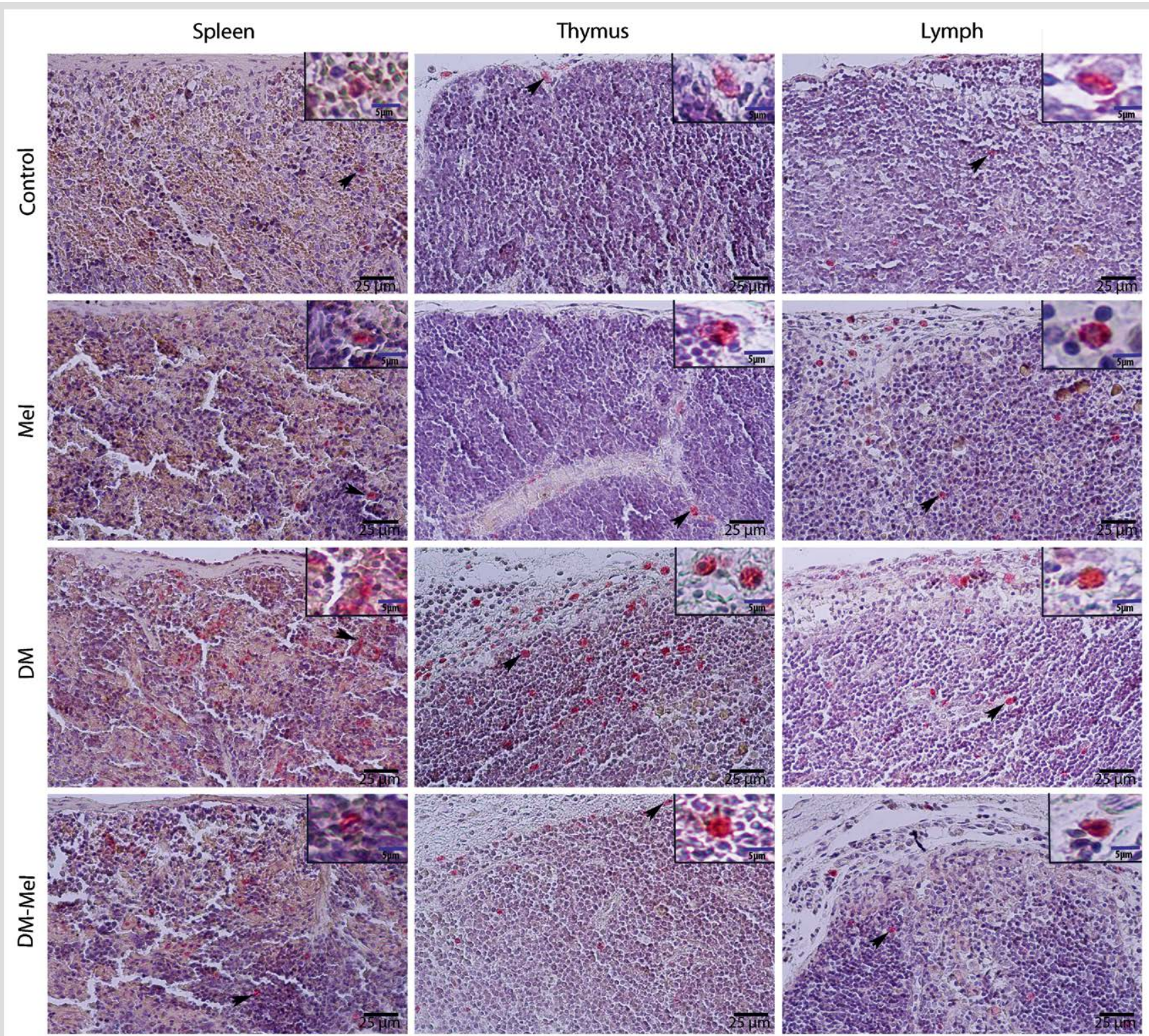

Fig. 4 Illustration of esterase positive mast cells (MCs) in the spleen, thymus, and lymph node of all groups, esterase enzyme staining. (Color figure available online only).

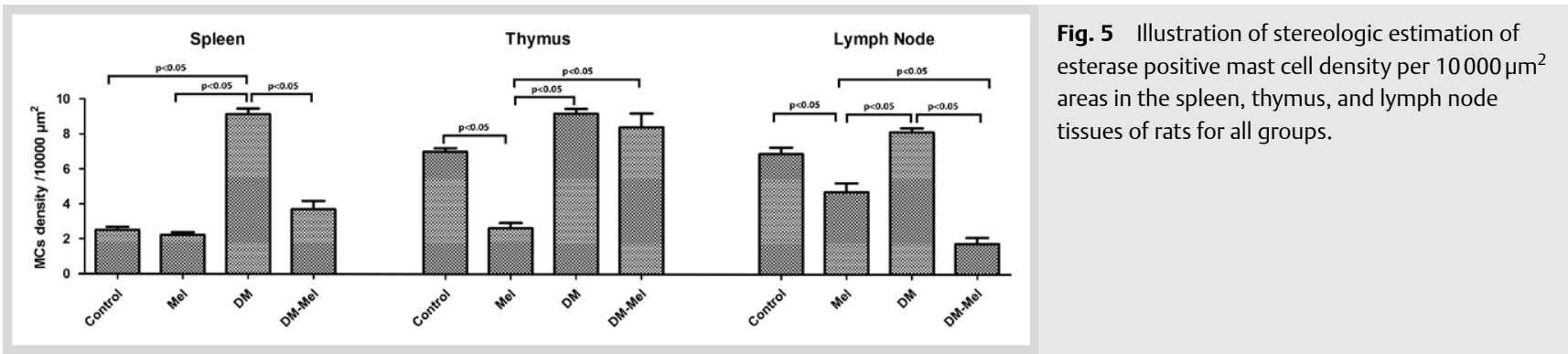

tissue [36] by direct action to the production of leukocytes [37]. The other possible mechanism is that melatonin may protect hematopoietic systems by scavenging free radicals due to its antioxidant features [17]. The present research showed that melatonin treatment significantly decreased leukocytogenesis in diabetic patients.

It is important to identify the pathogenic relationship between diabetes mellitus and cytokine activation. There is evidence that the cytotoxic actions of IL-1, TNF- $\alpha$, and IFN- $\gamma$ have been detected in islets cells of diabetic patients [9]. Increased inflammation and MC infiltration had an essential role in obesity and its associated complications. Shi and Shi have suggested that MCs may interact with inflammatory and noninflammatory cells by releasing inflammatory mediators [30]. However, inflammatory mediators originate from many cells such as macrophages and adipocytes. Additionally, it is reported that the expression of 
TNF- $\alpha$ by adipocytes provokes obesity and can lead to insulin resistance by interfering with insulin receptor tyrosine kinase activity [3] and polymorphisms in the promoters of TNF- $\alpha$ and IL-6, which were found to be associated with diabetes [11]. Previous studies have reported direct evidence for the process of such a cytokine immunoregulatory balance in the avoidance of autoimmune diabetes $[3,38]$. However, Rodriguez-Reynoso et al. reported the inhibitor effect of melatonin on TNF- $\alpha$ level depends on the energetic status of the liver [39]. Furthermore, numerous studies have shown the immune-modulatory action of melatonin in many diseases, including diabetes $[17,20]$. The findings of the present study revealed increased cytokine activations in the diabetic process and the treatment with melatonin slightly modulate the immune response of diabetes due to the possible immunomodulatory action of melatonin.

Mast cells have been reported to be potent effector cells in many autoimmune diseases, such as systemic lupus erythematous, multiple sclerosis, and T1DM [40]. MCs settle in connective tissues throughout the body, including the lymphoid organs [41], which are derived from hematopoietic CD34 ${ }^{+}$stem cells. MCs can produce many immune mediator substances and cell signaling molecules that are responsible for coordinating immune responses during inflammation [8]. Also, there is an interaction between MCs and T cells in T cell-related immune activation [42]. Previous studies have reported both an increase [43] and a decrease [7] in MC densities in diabetes mellitus, and these changes were associated with diabetes type, complications of diabetes, and applied diabetic agents [30]. Cikler et al. reported that melatonin treatment can decrease mast cells in the dermis in water avoidance stress-induced rats [44]. A decrease in melatonin levels has also been observed in many diseases, including Alzheimer's disease, a periodontitis rat model, and a diabetes rat model $[25,45]$, all of which would be logically related with direct or indirect inhibitory action of melatonin on mast cells. The findings of the present study are in agreement with the literature in that there were higher densities of MCs in the all-lymphoid organs. These results revealed the role of MCs in diabetic inflammation by T-cell mediated response; however, their role in diabetes progression remains unclear.

The histopathologic results of the present investigation revealed that melatonin treatment protects the lymphoid organs (lymph node, spleen, and thymus) from diabetic effects. Many studies have indicated that melatonin can decrease the free radical load via the underlying mechanism by which melatonin exerts its immune-potentiating action [19,46,47]. Melatonin MT1 and MT2 receptors are located on lymphoid organs, including the thymus and the spleen $[47,48]$, as well as the bursa of Fabricious in bird species, which suggests that melatonin might have a physiological process of lymphocyte regulation and immune response [48]. Also, the immunomodulatory action of melatonin has been summarized in many reviews regarding its importance from a systemic point of view as well as for its possible therapeutic relevance to cell protection and mitochondrial function $[32,49,50]$. These studies are in agreement with our study and have supported that the diabetic process may lead to pathologic processes by several mechanism, whereas melatonin treatment enhanced the cell defense due to its ability to restore antioxidants. Additionally, melatonin decreased the proliferation of splenocytes and type 1 helper cells [17].

In conclusion, the characteristics of immune response and MCmediated activation in diabetic pathogenesis underline the mechanisms by which this inflammation contributes to many tissues, including lymphoid organs. In addition, melatonin could be a candidate for the design of novel therapies to moderate diabetic inflammation through its immune-modulatory and/or antioxidant properties.

\section{Conflict of Interest \\ $\nabla$}

The authors declare no conflict of interest.

\section{Affiliations}

Department of Biochemistry, Faculty of Veterinary Medicine, University of Ataturk, Erzurum, Turkey

Department of Histology and Embryology, Faculty of Veterinary Medicine, University of Ataturk, Erzurum, Turkey

Department of Physiology, Faculty of Veterinary Medicine, University of Ataturk, Erzurum, Turkey

Department of Histology and Embryology, Faculty of Medicine, University of Balikesir, Balikesir, Turkey

Department of Physiology, Faculty of Medicine, University of Balikesir, Balikesir, Turkey

Department of Biochemistry, Faculty of Medicine, University of Ataturk, Erzurum, Turkey

\section{References}

1 Guay C, Regazzi R. Circulating microRNAs as novel biomarkers for diabetes mellitus. Nat Rev Endocrinol 2013; 9: 513-521

2 Ünal D, Kara A, Aksak S, Altunkaynak BZ, Yildrrm S. Insulin hormone: Mechanism and effects on the body and relationship with central nervous system. Dicle Med J/Dicle Tip Dergisi 2012; 39: 310-315

3 Wellen KE, Hotamisligil GS. Inflammation, stress, and diabetes. J Clin Invest 2005; 115: 1111-1119

4 Rabinovitch A, Suarez-Pinzon WL. Roles of cytokines in the pathogenesis and therapy of type 1 diabetes. Cell Biochem Biophys 2007; 48: 159-163

5 Tie L, Li XJ, Wang X, Channon KM, Chen AF. Endothelium-specific GTP cyclohydrolase I overexpression accelerates refractory wound healing by suppressing oxidative stress in diabetes. American journal of physiology Endocrinol Metab 2009; 296: E1423-E1429

6 Barreto EO, Riederer I, Arantes AC, Carvalho VF, Farias-Filho FA, Cordeiro RS, Martins MA, Savino W, eSilva PM. Thymus involution in alloxan diabetes: analysis of mast cells. Memorias do Instituto Oswaldo Cruz 2005; 100 (Suppl 1): 127-130

7 Diaz BL, Serra MF, Alves AC, Pires AL, Correa FM, Cordeiro RS, Martins MA, eSilva PM. Alloxan diabetes reduces pleural mast cell numbers and the subsequent eosinophil influx induced by allergen in sensitized rats. Int Arch Allergy Immunol 1996; 111: 36-43

8 Galli SJ, Nakae S, Tsai M. Mast cells in the development of adaptive immune responses. Nat Immunol 2005; 6: 135-142

9 Rabinovitch A, Suarez-Pinzon WL. Cytokines and their roles in pancreatic islet beta-cell destruction and insulin-dependent diabetes mellitus. Biochem Pharmacol 1998; 55: 1139-1149

10 Nishimura F, Iwamoto Y, Mineshiba J, Shimizu A, Soga Y, Murayama Y Periodontal disease and diabetes mellitus: the role of tumor necrosis factor-alpha in a 2-way relationship. J Periodontol 2003; 74: 97-102

11 Hotamisligil GS, Spiegelman BM. Tumor necrosis factor a: a key component of the obesity-diabetes link. Diabetes 1994; 43: 1271-1278

12 Mishima Y, Kuyama A, Tada A, Takahashi K, Ishioka T, Kibata M. Relationship between serum tumor necrosis factor-alpha and insulin resistance in obese men with Type 2 diabetes mellitus. Diabetes Res Clin Pract 2001; 52: 119-123

13 Leme JG, Hamamura L, Migliorini RH, Leite MP. Influence of diabetes upon the inflammatory response of the rat. A pharmacological analysis. Eur J Pharmacol 1973; 23: 74-81

14 Bozza PT, Castro-Faria-Neto HC, Penido C, Larangeira AP, Silva PM, Martins MA, Cordeiro RS. IL-5 accounts for the mouse pleural eosinophil accumulation triggered by antigen but not by LPS. Immunopharmacology 1994; 27: 131-136

15 Martins M, Lima M, Alves A, Diaz B, Cordeiro R. Pharmacological modulation of the late eosinophilia induced by antigen in actively sensitized rats. Int Arch Allergy Immunol 1992; 98: 355-360

16 Afzal R. Melatonin: Miracles far beyond the pineal gland. Indian J Endocrinol Metab 2012; 16: 672 
17 Carrillo-Vico A, Lardone PJ, Álvarez-Sánchez N, Rodríguez-Rodríguez A, Guerrero JM. Melatonin: buffering the immune system. Int J Mol Sci 2013; 14: 8638-8683

18 Reiter RJ, Tan DX, Mayo JC, Sainz RM, Leon J, Czarnocki Z. Melatonin as an antioxidant: biochemical mechanisms and pathophysiological implications in humans. Acta Biochim Pol 2003; 50: 1129-1146

19 Carrillo-Vico A, Guerrero JM, Lardone PJ, Reiter RJ. A review of the multiple actions of melatonin on the immune system. Endocrine 2005; 27: $189-200$

20 Kara A, Akman S, Ozkanlar S, Tozoglu U, Kalkan Y, Canakci CF, Tozoglu $S$. Immune modulatory and antioxidant effects of melatonin in experimental periodontitis in rats. Free Radical Biol Med 2013; 55: 21-26

21 Turgut M, Uyanikgil Y, Baka M, Tunc AT, Yavasoglu A, Yurtseven ME, Kaplan $S$. Pinealectomy exaggerates and melatonin treatment suppresses neuroma formation of transected sciatic nerve in rats: gross morphological, histological and stereological analysis. J Pineal Res 2005; 38: 284-291

22 Slominski AT, Kleszczyński K, Semak I, Janjetovic Z, Żmijewski MA, Kim T-K, Slominski RM, Reiter RJ, Fischer TW. Local melatoninergic system as the protector of skin integrity. Int J Mol Sci 2014; 15: 17705-17732

23 Slominski RM, Reiter RJ, Schlabritz-Loutsevitch N, Ostrom RS, Slominski $A T$. Melatonin membrane receptors in peripheral tissues: distribution and functions. Mol Cell Endocrinol 2012; 351: 152-166

24 Slominski A, Tobin DJ, Zmijewski MA, Wortsman J, Paus R. Melatonin in the skin: synthesis, metabolism and functions. Trends Endocrinol Metab 2008; 19: 17-24

25 Simsek N, Kaya M, Kara A, Can I, Karadeniz A, Kalkan Y. Effects of melatonin on islet neogenesis and beta cell apoptosis in streptozotocininduced diabetic rats: an immunohistochemical study. Domest Anim Endocrinol 2012; 43: 47-57

26 Carrillo-Vico A, Lardone PJ, Naji L, Fernández-Santos JM, Martín-Lacave I, Guerrero JM, Calvo JR. Beneficial pleiotropic actions of melatonin in an experimental model of septic shock in mice: regulation of pro-/ anti-inflammatory cytokine network, protection against oxidative damage and anti-apoptotic effects. J Pineal Res 2005; 39: 400-408

27 Kalkan Y, Kapakin KA, Kara A, Atabay T, Karadeniz A, Simsek N, Karakus E, Can I, Yildirim S, Ozkanlar S, Sengul E. Protective effect of Panax ginseng against serum biochemical changes and apoptosis in kidney of rats treated with gentamicin sulphate. J Mol Histol 2012; 43: 603-613

28 Unal B, Kara A, Unal D, Aksak S. A stereological assessment method for estimating the surface area of cycloids. Eurasian J Med 2010; 42: 66-73

29 Bach JF. Insulin-dependent diabetes mellitus as an autoimmune disease. Endocr Rev 1994; 15: 516-542

30 Shi MA, Shi GP. Different roles of mast cells in obesity and diabetes: lessons from experimental animals and humans. Front Immunol 2012; 3: 7

31 Kemmochi Y, Fukui K, Maki M, Kimura S, Ishii Y, Sasase T, Miyajima K, Ohta T. Metabolic Disorders and Diabetic Complications in Spontaneously Diabetic Torii Lepr (fa) Rat: A New Obese Type 2 Diabetic Model. J Diabetes Res 2013; 2013: 948257

32 Hardeland R, Cardinali DP, Srinivasan V, Spence DW, Brown GM, PandiPerumal SR. Melatonin - a pleiotropic, orchestrating regulator molecule. Prog Neurobiol 2011; 93: 350-384

33 Vishwas DK, Haldar C. Photoperiodic induced melatonin regulates immunity and expression pattern of melatonin receptor MT1 in spleen and bone marrow mononuclear cells of male golden hamster. J Photochem Photobiol B: Biol 2013; 128: 107-114
34 Anwar MM, Mahfouz HA, Sayed AS. Potential protective effects of melatonin on bone marrow of rats exposed to cytotoxic drugs. Comp Biochem Physiol Part A: Mol Integr Physiol 1998; 119: 493-501

35 Özçelik IS. Beneficial Effects of Melatonin on Oxidative Damage Observed During Whole Blood Storage. Uluslararası HematolojiOnkolojı Dergisi 2014; 24: 89-96

36 Zylinska K, Komorowski J, Robak T, Mucha S, Stepien H. Effect of granulocyte-macrophage colony stimulating factor and granulocyte colony stimulating factor on melatonin secretion in rats in vivo and in vitro studies. J Neuroimmunol 1995; 56: 187-190

37 Capelli E, Campo I, Panelli S, Damiani G, Barbone MG, Lucchelli A, Cuccia $M$. Evaluation of gene expression in human lymphocytes activated in the presence of melatonin. Int Immunopharmacol 2002; 2: 885-892

38 Fowell $D$, Mason $D$. Evidence that the T cell repertoire of normal rats contains cells with the potential to cause diabetes. Characterization of the CD4+ T cell subset that inhibits this autoimmune potential. J Exp Med 1993; 177: 627-636

39 Rodriguez-Reynoso S, Leal C, Portilla E, Olivares N, Muñiz J. Effect of exogenous melatonin on hepatic energetic status during ischemia/ reperfusion: possible role of tumor necrosis factor-a and nitric oxide. J Surg Res 2001; 100: 141-149

40 Benoist C, Mathis D. Mast cells in autoimmune disease. Nature 2002; 420: 875-878

41 Kunder CA St, John AL, Abraham SN. Mast cell modulation of the vascular and lymphatic endothelium. Blood 2011; 118: 5383-5393

42 Frandji P, Oskeritzian C, Cacaraci F, Lapeyre J, Peronet R, David B, Guillet $J$, Mecheri S. Antigen-dependent stimulation by bone marrow-derived mast cells of MHC class II-restricted T cell hybridoma. J Immunol 1993; 151: 6318-6328

43 Jones $S$, Gilbert $R$, Kelly D. Tranilast reduces mesenteric vascular collagen deposition and chymase-positive mast cells in experimental diabetes. J Diabetes Complicat 2004; 18: 309-315

44 Cikler E, Ercan F, Cetinel S, Contuk G, Sener G. The protective effects of melatonin against water avoidance stress-induced mast cell degranulation in dermis. Acta Histochem 2005; 106: 467-475

45 Rios ER, Venancio ET, Rocha NF, Woods DJ, Vasconcelos S, Macedo D, Sousa FC, Fonteles MM. Melatonin: pharmacological aspects and clinical trends. Int J Neurosci 2010; 120: 583-590

46 Sharma S, Haldar C. Melatonin prevents X-ray irradiation induced oxidative damagein peripheral blood and spleen of the seasonally breeding rodent, Funambulus pennanti during reproductively active phase. Int J Rad Biol 2006; 82: 411-419

47 Sanchez-Hidalgo M, Guerrero Montavez JM, Carrascosa-Salmoral Mdel $P$, Naranjo Gutierrez Mdel C, Lardone PJ, de la Lastra Romero CA. Decreased MT1 and MT2 melatonin receptor expression in extrapineal tissues of the rat during physiological aging. J Pineal Res 2009; 46: $29-35$

48 Calvo JR, Rafii-el-Idrissi M, Pozo D, Guerrero JM. Immunomodulatory role of melatonin: specific binding sites in human and rodent lymphoid cells. J Pineal Res 1995; 18: 119-126

49 Guerrero JM, Reiter RJ. Melatonin-immune system relationships. Curr Top Med Chem 2002; 2: 167-179

50 Cardinali DP, Esquifino AI, Srinivasan V, Pandi-Perumal SR. Melatonin and the immune system in aging. Neuroimmunomodulation 2008; 15: $272-278$ 